\title{
Digital PCR as a tool to measure HIV persistence
}

\author{
Sofie Rutsaert ${ }^{1 \dagger}$, Kobus Bosman $^{2 \dagger}$, Wim Trypsteen ${ }^{1}$, Monique Nijhuis ${ }^{2}$ and Linos Vandekerckhove ${ }^{1 *} \mathbb{D}$
}

\begin{abstract}
Although antiretroviral therapy is able to suppress HIV replication in infected patients, the virus persists and rebounds when treatment is stopped. In order to find a cure that can eradicate the latent reservoir, one must be able to quantify the persisting virus. Traditionally, HIV persistence studies have used real-time PCR (GPCR) to measure the viral reservoir represented by HIV DNA and RNA. Most recently, digital PCR is gaining popularity as a novel approach to nucleic acid quantification as it allows for absolute target quantification. Various commercial digital PCR platforms are nowadays available that implement the principle of digital PCR, of which Bio-Rad's QX200 ddPCR is currently the most used platform in HIV research. Quantification of HIV by digital PCR is proving to be a valuable improvement over qPCR as it is argued to have a higher robustness to mismatches between the primers-probe set and heterogeneous HIV, and forfeits the need for a standard curve, both of which are known to complicate reliable quantification. However, currently available digital PCR platforms occasionally struggle with unexplained false-positive partitions, and reliable segregation between positive and negative droplets remains disputed. Future developments and advancements of the digital PCR technology are promising to aid in the accurate quantification and characterization of the persistent HIV reservoir.
\end{abstract}

Keywords: Digital PCR, HIV, ddPCR

\section{Background}

During antiretroviral therapy (ART), HIV can persist for decades in latently infected CD4 $+\mathrm{T}$ cells as proviral DNA integrated in the human genome. If ART is interrupted, the proviral reservoir fuels rebound viremia and is therefore considered a major obstacle to HIV cure [1]. HIV cure efforts aim to reduce the size and replicationcompetence of the reservoir by evaluating the success of HIV cure interventions, which is represented by an effect on the level of proviral DNA and/or cell-associated viral RNA. The standard tool to quantify HIV DNA and cellassociated viral RNA has been real-time PCR (qPCR). However, digital PCR has become a promising quantification strategy that combines absolute quantification with high sensitivity [2]. Digital PCR is based on the concept of limiting dilution where target molecules are

\footnotetext{
*Correspondence: Linos.Vandekerckhove@UGent.be

† Sofie Rutsaert and Kobus Bosman have contributed equally to this work

${ }^{1}$ HIV Cure Research Center, Department of Internal Medicine, Ghent

University, Ghent, Belgium

Full list of author information is available at the end of the article
}

randomly divided among a multitude of partitions. After PCR amplification, partitions that contain a target molecule accumulate fluorescence whereas partitions without target remain low in fluorescence (Fig. 1). A threshold is applied to the partitions, which divides the partitions into a positive and a negative population. The ratio between the number of positive and negative partitions is used to calculate the absolute number of target molecules, corrected for the chance that partitions are shared by multiple target molecules by the Poisson distribution law [2]. The first steps towards digital PCR were taken 30 years ago when the concept of limiting dilution and Poisson distribution were applied to detect rare targets [3-5]. In the field of HIV research, Simmonds et al. [6] combined PCR with limiting dilution to quantify the proviruses in HIV-infected cells. The term 'digital PCR' was introduced by Vogelstein in [7] to identify specific mutated sequences in a minor fraction of a cell population. Nowadays digital PCR is a widely accepted quantification tool and applied in many fields. 


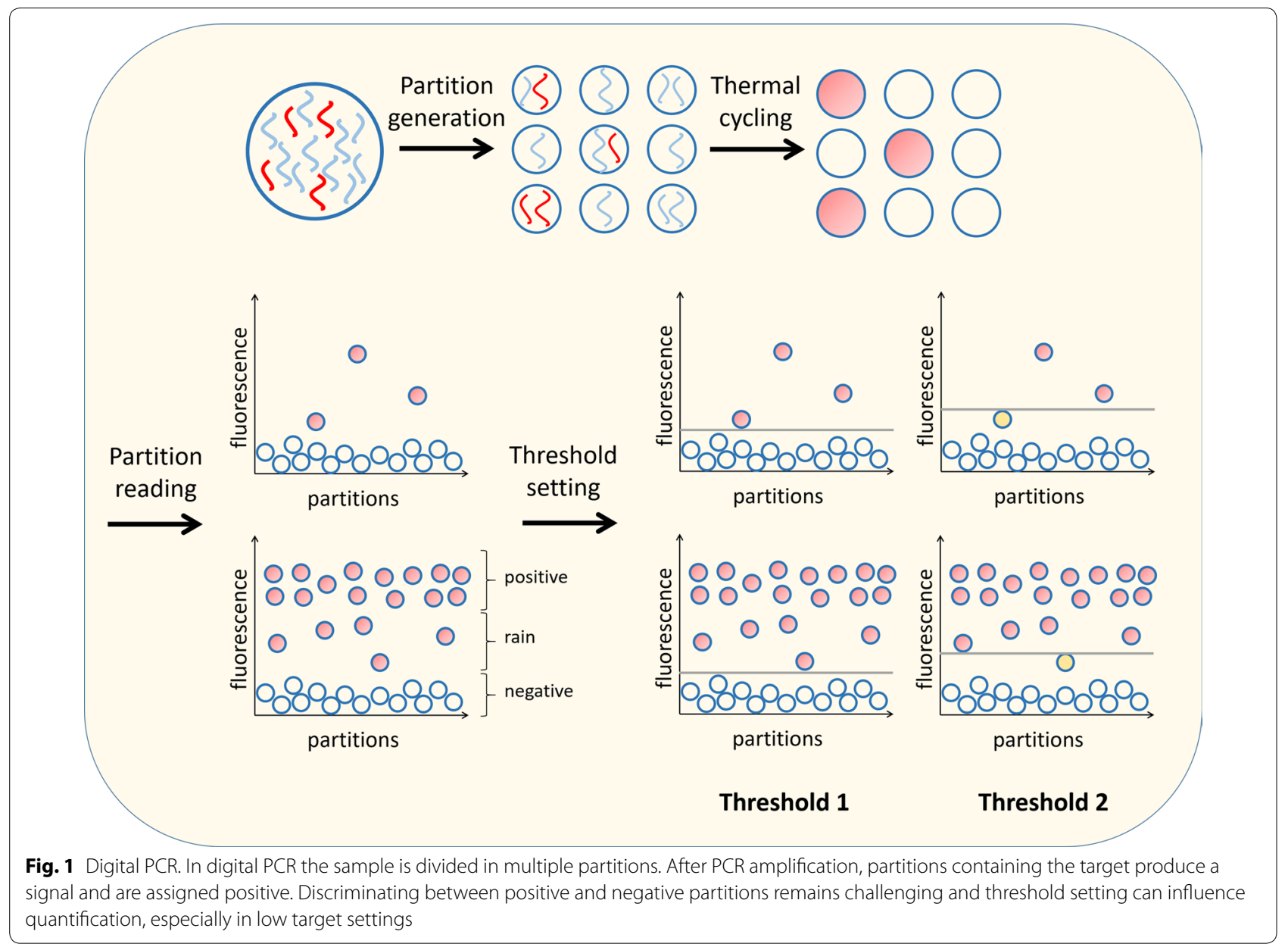

\section{Digital PCR platforms}

The key principle of digital PCR is the distribution of a sample among multiple partitions. Originally, partitions were created by manually distributing a sample over a number of wells [7]. Nowadays, manual partitioning is applied in case of complex protocols with a nested approach that cannot be adopted to an automated platform, such as the digital PCR described as a manual repetitive sampling protocol that is used to measure integrated HIV DNA [8, 9]. However, manually generating multiple partitions is very time-consuming and laborious. The past decade automated systems have emerged and different technologies and methods are being explored by various companies for digitizing PCR (for an overview, see Table 1). Currently available digital platforms differ in number of partitions, method of generating partitions or required specialized equipment. Partitions can be generated in a pre-manufactured array: BioMark $^{\mathrm{TM}}$ HD System (Fluidigm) provides a wide range of specialized digital integrated fluidic circuits (IFCs) arrays where the sample is dispensed in a well and distributed over multiple individual reaction chambers. QuantStudio 3D (Life Technologies/Applied Biosystems ${ }^{\mathrm{TM}}$ ) employs a silicon chip that consists of a single array of individual reaction wells onto which the sample is dispensed. CONSTELLATION $^{\circledR}$ Digital PCR System (Formulatrix) utilizes a microplate where connecting channels are isolated into individual microfluidic chambers by a seal-compressing roller. In contrast to these array-based approaches, other digital PCR platforms such as the QX200 ${ }^{\mathrm{TM}}$ Droplet Digital ${ }^{\mathrm{TM}}$ PCR (ddPCR) and RainDrop plus $^{\text {TM }}$ Digital PCR system (RainDance ${ }^{\mathrm{TM}}$ technologies) use water-in-oil emulsion chemistry to create partitions. The aqueous phase consisting of primers, probe and supermix, sample, and a mineral oil is loaded into a specifically designed holder. The droplet generator uses microfluidics to create a pressure that draws the aqueous and oil phase into the output channel, forming the droplets in the process. Each droplet is read one by one in a specialized droplet reader. Finally, Naica system from Stilla combines both the array and emulsion approaches. 


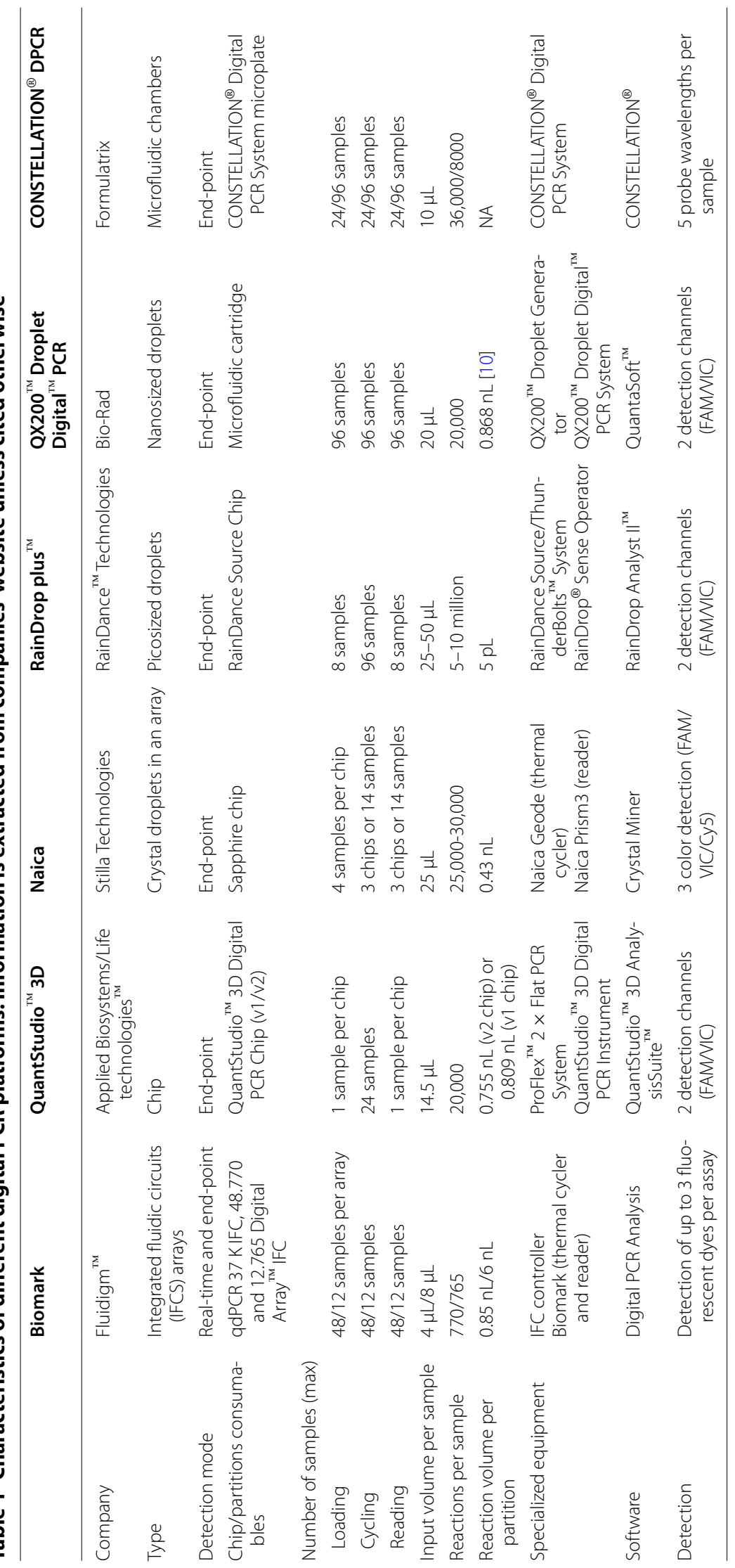


In this system, a sample runs through the channels of a chip and droplets are created inside the chip.

\section{Challenges and benefits of droplet digital PCR}

There are multiple digital PCR platforms, but over the past years, the QX200 has steadily become the most widely used digital PCR platform across all research fields (Fig. 2). Therefore, in this review we will focus on the QX200 ddPCR from Bio-Rad to discuss challenges and benefits of digital PCR. It should however be noted that challenges with threshold determination and falsepositives are not exclusively observed with the ddPCR from Bio-Rad but seem to be related to other digital platforms as well [11-15].

\section{Threshold determination}

In ddPCR generated droplets are identified as positive or negative based on a threshold at a certain fluorescence level and this ratio is used to calculate target abundance using Poisson-statistics. Therefore, determining a correct threshold is crucial for reliable quantification (Fig. 1). Defining a threshold is complicated by droplets with an intermediate fluorescence, termed as rain, which are puzzling to assign to the either positive or negative population. For the frequently used Bio-Rad ddPCR system, the QuantaSoft software offers an undisclosed method for automated threshold assignment and manual threshold setting by the end-user. The automated analysis often assigns thresholds so strict that a cloud of droplets is appointed positive that based on their low fluorescence is expected to be negative [16]. Alternatively, user-defined thresholds may be applied but these are generally not advised as they impair an unbiased interpretation of digital PCR data. Threshold setting can be challenging since the separation between positive and negative droplets may depend on many factors, such as the quality and quantity of the input sample, melting temperature and length of primers and probe, mismatches between the assay and target sequences, time between droplet generation and readout, pipetting precision, type of fluorescent reporter and type of quencher. Several algorithms have been developed by end-users that aim to offer more data-driven approaches to set thresholds. First, clustering methods were developed by Strain et al. and Jones et al. based on k-nearest neighbor-joining $[17,18]$. The method of Strain et al. defines the median and variance of the negative and positive clouds to assess the statistical likelihood that outliers should be included in either cloud $(p<0.1)$. Jones et al. developed "definetherain" that uses negative and positive control samples to identify the two clouds. Subsequently, the mean fluorescence minus or plus three times its standard deviation is used as thresholds that are applied to the samples. Both these clustering methods calculate a threshold for each cloud of droplets and exclude intermediate fluorescent droplets from further analysis. In contrast, Dreo et al. proposed a single threshold determination method since droplets with intermediate fluorescence intensity can hold true positive droplets $[19,20]$. This global manual threshold is defined as the mean fluorescence signal in the NTCs (no template controls) plus a number of standard deviations until one positive droplet remains in the NTCs [19]. These described methods assume a normal (binomial) distribution of the negative and positive clouds and do not account for shifts in baseline fluorescence between droplet populations of different samples. However, distribution fitting experiments and normality testing shows that droplet clouds do not follow a normal distribution and cannot be described by a single family of distributions. Furthermore, baseline fluorescence of the negative cloud has been shown to vary between samples and influence quantification [16]. Therefore, an alternative

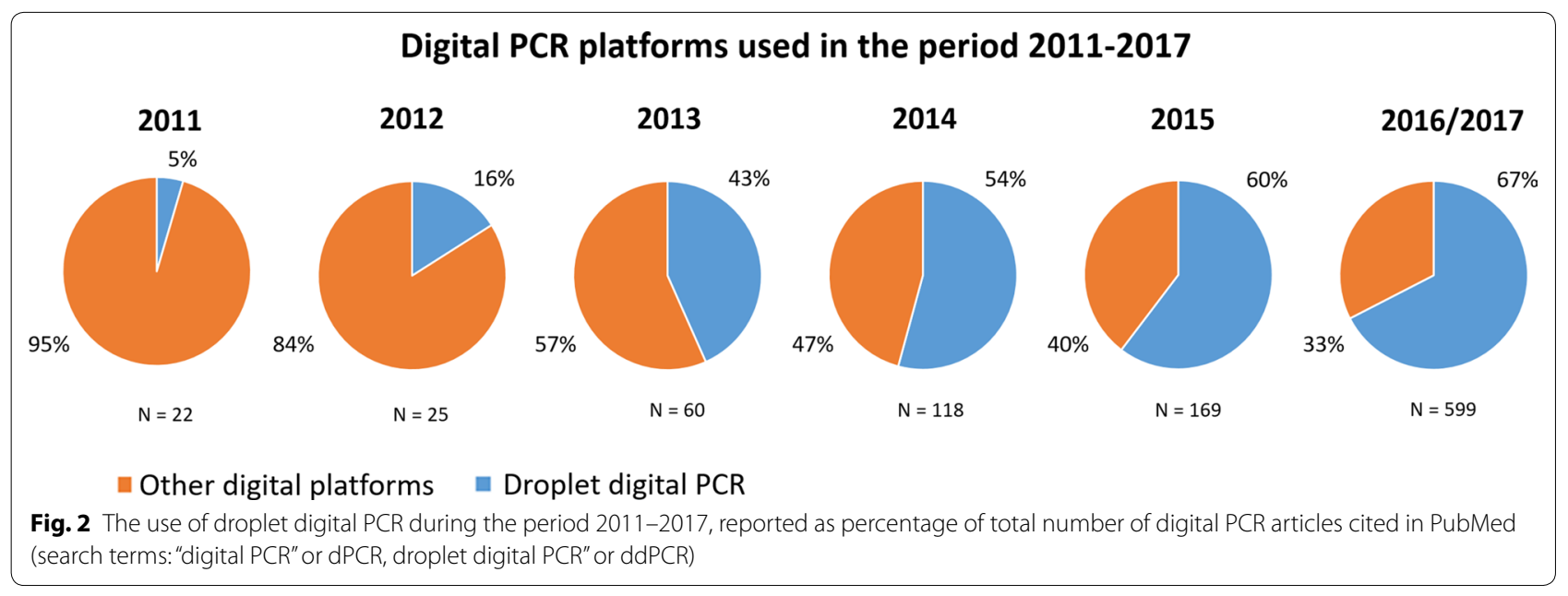


thresholding method was devised by Trypsteen et al. [16] that assigns a threshold regardless of the many factors that may affect the intensity and distribution of droplet fluorescence. This method, ddpcRquant, feeds data from negative controls to a generalized extreme value model and applies this threshold to the samples. The algorithm does not make assumptions of the underlying distribution of the droplet populations and accounts for baseline shifts. Alternatively, Lievens et al. [20] determine the threshold based on the shape of the fluorescence density peaks but to account for the possibility that clouds are not normally distributed set the threshold above the uppermost limit of the negative cloud. Recently, a novel method, "Umbrella", was published that does not apply hard thresholding, but applies a model-based clustering and takes partition-specific classification probabilities into account to produce a final quantification result [21]. Threshold setting remains a challenging but crucial task. It is difficult to establish whether or not intermediate droplets represent true targets that should be used for analysis, since the current generation of ddPCR is not fitted with a fluorescence intensity sorter to allow for target confirmation by for example sequencing. Recent evidence however suggests that intermediate droplets should be considered to contain target molecules, as decreased amplification efficiency may arise from a suboptimal annealing temperature [22] or mismatches between the assay and the target sequence [16]. Furthermore, several studies that investigated ddPCR sensitivity have used a user-defined threshold that allocates rain to the positive fraction of droplets, and doing so have found results that are on par with the input reference and qPCR results $[11,20,23,24]$.

\section{False-positives}

Regardless of the method that is used to assign a threshold, currently available digital PCR platforms including the QX200 suffer from the observation of false-positive partitions and therefore false-positive results [11, 16, 18, 23-25]. One out of three wells of negative controls with no template had 2 or 3 positive droplets $(0.16-0.22$ copies/reaction) for HIV-1 RNA assay described by Kiselinova et al. [23]. These droplets had a similar fluorescence level as positive droplets in patients samples. The origin of these errors remains unclear and various hypotheses have been proposed. False-positive droplets can arise from contaminations or disturbed droplets that merge together, their joint fluorescence leading to a droplet with a higher baseline fluorescence that is miscalled as positive.

False-positive droplets can pose a threat to reliable HIV DNA quantification in settings with low HIV DNA concentrations such as mother-to-child transmission, early treatment initiation and allogeneic stem cell transplantation (alloSCT). AlloSCT is currently the only known approach by which the HIV reservoir can be drastically reduced. Following a successful stem cell transplantation, patients are kept on ART and are monitored for HIV DNA levels, but reliable ascertainment of remainder HIV DNA is a challenge, especially when the interpretation of true-positive droplets is obscured by false-positive ones. Same holds true for ART-treated children, which may have initiated ART early after birth based on the HIV-status of their mother whereas uncertainty may exist if the infection was transmitted from mother to child. In these seronegative children, HIV DNA is the only proof of HIV infection and therefore the only justification for treatment with ART. However, confirmation of the presence of HIV DNA is challenging since patients who initiated ART early after infection are known to have small reservoirs and sample volumes are restricted in case of young children, which reduces the statistical power to assess the presence of HIV DNA. Therefore, false-positives can unrightfully lead to confirmation of HIV infection and continuation of ART and it is not advised to use digital PCR if the question is to discriminate between presence or absence of HIV DNA [11]. Since only a minor fraction of all potential CD4 positive target cells carry HIV DNA, a large number of cells need to be tested in order to be able to reliably quantify HIV DNA concentrations. High concentrations of total DNA however affect the viscosity of the aqueous phase and complicate the formation of droplets. The amount of DNA that can be loaded into a single reaction is therefore restricted $[18,26]$. Researchers who aim to report an HIV DNA concentration in a million CD4-cells are required to split the target DNA among a number of reactions, thereby increasing the risk of detecting false-positive droplets and influencing final HIV DNA concentration outcome. This effect is even greater when samples are used in which HIV DNA is even less abundant, such as PBMCs, whole blood, dried blood spots or tissue biopsies.

\section{Advantages}

Apart from the issue of false-positives, digital PCR has shown to be equal or superior to qPCR in several aspects. One major advantage is that digital PCR produces direct absolute quantification. The absolute quantification results produced by digital PCR eliminate the need for a standard curve in case of DNA quantifications and comparisons of RNA quantifications. Of note, RNA quantification represents cDNA molecules and should therefore be corrected for cDNA synthesis efficiency [27]. Accurate quantification by qPCR is based on the quality of the standard curve: instability of the standard curve can lead to inaccurate HIV DNA quantification 
[28]. Additionally, Cq values in qPCR that arise from the standard and the samples are based on amplification efficiencies, and several factors may confound their correct interpretation. Amplification efficiency may be affected by inhibitors, amount of total DNA that is loaded as well as variation between the primer/probe and the patient's viral sequence, and these factors may unrightfully elevate the $\mathrm{Cq}$ values. In $\mathrm{qPCR}$, such mismatches would increase the $\mathrm{Cq}$ and in turn present a target abundance that is lower than the actual input. In ddPCR however, a reduced amplification efficiency leads to less fluorescence at end-point. As long as end-point fluorescence remains above the assigned threshold and the ratio between positive and negative fraction of droplets is unaltered, mismatches between assay and target are allowed as they do not affect the quantification outcome $[16,29,30]$. Tolerance to target sequence variation is especially crucial for HIV quantification as a higher chance of mismatches with the primer-probe set is to be expected due to high heterogeneity of the virus [31]. Besides the robustness of ddPCR with respect to inhibition and reduced amplification efficiency, a higher precision and reproducibility was observed for ddPCR in comparison to qPCR [18, 32]. This is especially crucial in HIV cure efforts where the aim is to detect potential effects of the interventions on the HIV reservoir. However, it is important to note here that contradicting findings have been published that observed a higher sensitivity of the qPCR platform [23, 33]. In duplex digital PCR experiments on linked targets, a minority of partitions was observed in which only one out of two assays demonstrated amplification [34]. It remains however unclear whether this observation is artificial due to DNA shearing and physical separation of supposed linked targets, or genuine failure to amplify due to assay-specific inhibitors, DNA degradation or tertiary structures. Furthermore, in case of genuine failure to amplify it is currently unclear whether this potential mode of target underestimation pertains to digital PCR alone or if similar mechanisms are at play in case of (q) PCR.

\section{Applicability and future perspectives}

HIV reservoir measurement by digital PCR has been used to measure the effects of early treatment initiation [35-38], therapeutic vaccination [39-41], allogenic stem cell transplantation [42], structured treatment interruptions [40, 43], immunization by broadly neutralizing antibodies [44], latency reversing agents (LRA's) [41, 45-49], and other novel therapeutic agents [50-52]. The concept of digital PCR is well-established but automated platforms and implementations in HIV quantification are relatively recent and the field is looking forward to future advancements. Where some platforms limit the number of specialized devices needed (CONSTELLATION ${ }^{\circledR}$ Digital PCR System microplate from Formulatrix), other companies are working on a multiplex system up to 6 colors (Naica system from Stilla) or enable the analysis of multiple samples in a single run (QX200 from BioRad). The combination of these features combined in a single device with a high-throughput workflow and elaborate multiplex system is desired. In addition, data analysis and threshold setting should be further developed in order to keep up with advances in multiplexing. Considering the observed false-positive partitions in current digital PCR platforms, quality control of the partitions is crucial. Naica system from Stilla currently allows visual inspection of the size and geometry of a single crystal droplet and the exclusion of those that are aberrant. The QX200 digital PCR platform may benefit from an integrated fluorescence sorter for post-PCR analysis of droplets. Such a feature would improve our understanding of the nature of suspected false-positive droplets by allowing post-PCR sequencing to verify if fluorescence is the cause of PCR or rather through the acquisition of fluorescent dust or debris. In addition, post-PCR sorting of single-cell droplets may improve our understanding of the dynamics involved in latency [47]. Yucha et al. demonstrated that the QX200 cartridge can be used to create single-cell-droplets, after which HIV RNA was quantified using standard digital PCR protocol. Using a blunt needle, they manually selected positive droplets for post-PCR sequencing of HIV ENV and human CCR5, and future experiments may even investigate HIV integration site or viral protein production. This holistic approach to HIV latency research holds great promise, yet requires specialized equipment and trained personnel and would therefore benefit from a fluorescence sorter that is integrated into the QX200 reader. Although digital PCR allows the precise quantification of HIV DNA and RNA in patients, it does not enable researchers to gain information about the replication-competence of the reservoir. Whereas the cell culture based viral outgrowth assay is an underestimation of the true viral reservoir, HIV measured by PCR is an overestimation because it counts the non-replication competent viruses as well [53]. Multiplexed ddPCR may however improve our understanding of the gap between viral outgrowth and PCR-based assays. Anderson et al. [54] used a multiplexed ddPCR to observe an increase of the LTR:gag ratio during time on treatment, which can be explained by elimination of replication-competent viruses or clonal expansion of non-replication competent viruses. Additionally, multiplexed ddPCR could aid in determining the number of times an HIV sequence 
has been clonally expanded. Clonal expansion and its specific HIV integration site is an international focus point since it is linked to persistence of HIV-infected cells [55]. However, integration site analysis is laborious and expensive but designing a multiplex ddPCR that targets HIV and the human sequence adjacent to HIV, clonal expansion of that specific HIV sequence can be calculated based on the increase of double-positive droplets relative to expected number based on chance [56]. In summary, digital PCR has proven to be a valuable new technology and with additional improvements in prospect it is likely to mature into an indispensable tool in future HIV research.

\section{Abbreviations}

ART: antiretroviral therapy; ddPCR: droplet digital PCR; qPCR: real-time PCR; LRA: latency reversing agent.

\section{Authors' contributions}

SR, KB, MN and LV discussed and decided on the outline of the review. SR performed the digital platform investigations and subsequent table. SR and WT made the figures. KB focused on challenges of ddPCR under guidance of MN and WT. SR was responsible for the cohesiveness and final form under guidance of LV. All authors read and approved the final manuscript.

\section{Author details}

${ }^{1}$ HIV Cure Research Center, Department of Internal Medicine, Ghent University, Ghent, Belgium. ${ }^{2}$ Department of Medical Microbiology, Virology, UMC Utrecht, Utrecht, The Netherlands.

\section{Acknowledgements}

Not applicable.

\section{Competing interests}

The authors declare that they have no competing interests.

\section{Availability of data and materials}

Not applicable.

\section{Consent for publication}

Not applicable.

\section{Ethics approval and consent to participate}

Not applicable.

\section{Funding}

L. Vandekerckhove is funded by the Research Foundation Flanders (FWO 1.8.020.09.N.00). S. Rutsaert received a strategic basic research fund of the Research Foundation Flanders (FWO, 1S32916N). K. Bosman and M. Nijhuis received funding from Aidsfonds Project (P-2013034) and amfAR ARCHE (Grant-ID109552-61-RSRL) (IciStem). M. Nijhuis is funded by Aidsfonds Project (P-13204). The authors have no other relevant affiliations or financial involvement with any organization or entity with a financial interest in or financial conflict with the subject matter or materials discussed in the manuscript apart from those disclosed. No writing assistance was utilized in the production of this manuscript.

\section{Publisher's Note}

Springer Nature remains neutral with regard to jurisdictional claims in published maps and institutional affiliations.

Received: 20 October 2017 Accepted: 19 January 2018

Published online: 30 January 2018

\section{References}

1. Chun T-W, Stuyver L, Mizell SB, Ehler LA, Mican JAM, Baseler M, et al. Presence of an inducible HIV-1 latent reservoir during highly active antiretroviral therapy. Proc Natl Acad Sci. 1997;94:13193-7.

2. Hindson BJ, Ness KD, Masquelier DA, Belgrader P, Heredia NJ, Makarewicz $\mathrm{AJ}$, et al. High-throughput droplet digital PCR system for absolute quantitation of DNA copy number. Anal Chem. 2011;83:8604-10.

3. Ruano G, Kidd KK, Stephens JC. Haplotype of multiple polymorphisms resolved by enzymatic amplification of single DNA molecules. Proc Natl Acad Sci USA. 1990;87:6296-300.

4. Saiki RK, Gelfand DH, Stoffel S, Scharf SJ, Higuchi R, et al. Primer-directed enzymatic amplification of dna with a thermostable DNA polymerase. Sci Wash. 1988;239:487.

5. Sykes PJ, Neoh SH, Brisco MJ, Hughes E, Condon J, Morley AA. Quantitation of targets for PCR by use of limiting dilution. Biotechniques. 1992;13:444-9.

6. Simmonds P, Balfe P, Peutherer JF, Ludlam CA, Bishop JO, Brown AJ. Human immunodeficiency virus-infected individuals contain provirus in small numbers of peripheral mononuclear cells and at low copy numbers. J Virol. 1990;64:864-72.

7. Vogelstein B, Kinzler KW. Digital PCR. Proc Natl Acad Sci. 1999;96:9236-41.

8. Agosto LM, Yu JJ, Dai J, Kaletsky R, Monie D, O'Doherty U. HIV-1 integrates into resting CD4 + T cells even at low inoculums as demonstrated with an improved assay for HIV-1 integration. Virology. 2007;368:60-72.

9. Spiegelaere WD, Malatinkova E, Lynch L, Nieuwerburgh FV, Messiaen P, O'Doherty U, et al. Quantification of integrated HIV DNA by repetitivesampling Alu-HIV PCR on the basis of poisson statistics. Clin Chem. 2014;60:886-95.

10. Pinheiro LB, Coleman VA, Hindson CM, Herrmann J, Hindson BJ, Bhat S, et al. Evaluation of a droplet digital polymerase chain reaction format for DNA copy number quantification. Anal Chem. 2012;84:1003-11.

11. Bosman KJ, Nijhuis M, van Ham PM, Wensing AMJ, Vervisch K, Vandekerckhove $L$, et al. Comparison of digital PCR platforms and semi-nested qPCR as a tool to determine the size of the HIV reservoir. Sci Rep. 2015;5:13811.

12. Lee H, Park Y-M, We Y-M, Han DJ, Seo J-W, Moon H, et al. Evaluation of digital PCR as a technique for monitoring acute rejection in kidney transplantation. Genom Inform. 2017;15:2-10.

13. Madic J, Zocevic A, Senlis V, Fradet E, Andre B, Muller S, et al. Three-color crystal digital PCR. Biomol Detect Quantif. 2016;10:34-46.

14. Papić B, Pate M, Henigman U, Zajc U, Gruntar I, Biasizzo M, et al. New approaches on quantification of Campylobacter jejuni in poultry samples: the use of digital PCR and real-time PCR against the ISO standard plate count method. Front Microbiol. 2017:8:331.

15. Wang Y, Tsang JYS, Cui Y, Cui J, Lin Y, Zhao S, et al. Robust and accurate digital measurement for HER2 amplification in HER2 equivocal breast cancer diagnosis. Sci Rep. 2017;7:6752.

16. Trypsteen W, Vynck M, Neve JD, Bonczkowski P, Kiselinova M, Malatinkova E, et al. ddpcRquant: threshold determination for single channel droplet digital PCR experiments. Anal Bioanal Chem. 2015;407:5827-34.

17. Jones M, Williams J, Gärtner K, Phillips R, Hurst J, Frater J. Low copy target detection by droplet digital PCR through application of a novel open access bioinformatic pipeline, 'definetherain'. J Virol Methods. 2014;202:46-53.

18. Strain MC, Lada SM, Luong T, Rought SE, Gianella S, Terry VH, et al. Highly precise measurement of HIV DNA by droplet digital PCR. PLOS ONE. 2013;8:e55943.

19. Dreo T, Pirc M, Ramšak Ž, Pavšič J, Milavec M, Žel J, et al. Optimising droplet digital PCR analysis approaches for detection and quantification of bacteria: a case study of fire blight and potato brown rot. Anal Bioanal Chem. 2014;406:6513-28.

20. Lievens A, Jacchia S, Kagkli D, Savini C, Querci M. Measuring digital PCR quality: performance parameters and their optimization. PLoS ONE. 2016;11:e0153317.

21. Jacobs BKM, Goetghebeur E, Vandesompele J, De Ganck A, Nijs N, Beckers A, et al. Model-based classification for digital PCR: your umbrella for rain. Anal Chem. 2017:89:4461-7.

22. Taylor SC, Carbonneau J, Shelton DN, Boivin G. Optimization of droplet digital PCR from RNA and DNA extracts with direct comparison to RT-qPCR: clinical implications for quantification of Oseltamivir-resistant subpopulations. J Virol Methods. 2015;224:58-66. 
23. Kiselinova M, Pasternak AO, De Spiegelaere W, Vogelaers D, Berkhout B, Vandekerckhove L. Comparison of droplet digital PCR and seminested real-time PCR for quantification of cell-associated HIV-1 RNA. PLOS ONE. 2014;9:e85999.

24. Henrich TJ, Gallien S, Li JZ, Pereyra F, Kuritzkes DR. Low-level detection and quantitation of cellular HIV-1 DNA and 2-LTR circles using droplet digital PCR. J Virol Methods. 2012;186:68-72.

25. Vynck M, Trypsteen W, Thas O, Vandekerckhove L, De Spiegelaere W. The future of digital polymerase chain reaction in virology. Mol Diagn Ther. 2016;20:437-47

26. Malatinkova E, Kiselinova M, Bonczkowski $P$, Trypsteen W, Messiaen $P$, Vermeire J, et al. Accurate quantification of episomal HIV-1 two-long terminal repeat circles by use of optimized DNA isolation and droplet digital PCR. J Clin Microbiol. 2015;53:699-701.

27. Sanders R, Mason DJ, Foy CA, Huggett JF. Evaluation of digital PCR for absolute RNA quantification. PLoS ONE. 2013;8:e75296.

28. Busby E, Whale AS, Ferns RB, Grant PR, Morley G, Campbell J, et al. Instability of $8 \mathrm{E} 5$ calibration standard revealed by digital PCR risks inaccurate quantification of HIV DNA in clinical samples by qPCR. Sci Rep. 2017;7:1209.

29. Dingle TC, Sedlak RH, Cook L, Jerome KR. Tolerance of droplet-digital PCR vs real-time quantitative PCR to inhibitory substances. Clin Chem. 2013;59:1670-2

30. Taylor SC, Laperriere G, Germain H. Droplet Digital PCR versus qPCR for gene expression analysis with low abundant targets: from variable nonsense to publication quality data. Sci Rep. 2017;7:2409.

31. McNearney T, Hornickova Z, Markham R, Birdwell A, Arens M, Saah A, et al. Relationship of human immunodeficiency virus type 1 sequence heterogeneity to stage of disease. Proc Natl Acad Sci USA. 1992;89:10247-51.

32. Hindson CM, Chevillet JR, Briggs HA, Gallichotte EN, Ruf IK, Hindson BJ, et al. Absolute quantification by droplet digital PCR versus analog realtime PCR. Nat Methods. 2013;10:1003-5.

33. Hayden RT, Gu Z, Ingersoll J, Abdul-Ali D, Shi L, Pounds S, et al. Comparison of droplet digital PCR to real-time PCR for quantitative detection of cytomegalovirus. J Clin Microbiol. 2013;51:540-6.

34. Whale AS, Cowen S, Foy CA, Huggett JF. Methods for applying accurate digital PCR analysis on low copy DNA samples. PLoS ONE. 2013;8:e58177.

35. Malatinkova E, Spiegelaere WD, Bonczkowski P, Kiselinova M, Vervisch K, Trypsteen W, et al. Impact of a decade of successful antiretroviral therapy initiated at HIV-1 seroconversion on blood and rectal reservoirs. eLife. 2015:4:e09115.

36. Buzon MJ, Martin-Gayo E, Pereyra F, Ouyang Z, Sun H, Li JZ, et al. Longterm antiretroviral treatment initiated at primary HIV-1 infection affects the size, composition, and decay kinetics of the reservoir of HIV-1-infected CD4 T cells. J Virol. 2014;88:10056-65.

37. Henrich TJ, Hatano H, Bacon O, Hogan LE, Rutishauser R, Hill A, et al. HIV-1 persistence following extremely early initiation of antiretroviral therapy (ART) during acute HIV-1 infection: an observational study. PLOS Med. 2017;14:e1002417.

38. Oliveira MF, Chaillon A, Nakazawa M, Vargas M, Letendre SL, Strain MC, et al. Early antiretroviral therapy is associated with lower HIV DNA molecular diversity and lower inflammation in cerebrospinal fluid but does not prevent the establishment of compartmentalized HIV DNA populations. PLoS Pathog. 2017;13:e1006112.

39. Hancock G, Morón-López S, Kopycinski J, Puertas MC, Giannoulatou E, Rose A, et al. Evaluation of the immunogenicity and impact on the latent HIV-1 reservoir of a conserved region vaccine, MVA. HIVconsv, in antiretroviral therapy-treated subjects. J Int AIDS Soc. 2017;20:21171.
40. Rosás-Umbert M, Mothe B, Noguera-Julian M, Bellido R, Puertas MC, Carrillo J, et al. Virological and immunological outcome of treatment interruption in HIV-1-infected subjects vaccinated with MVA-B. PLoS ONE. 2017;12:e0184929.

41. Mothe B, Climent N, Plana M, Rosàs M, Jiménez JL, Muñoz-Fernández MÁ, et al. Safety and immunogenicity of a modified vaccinia Ankara-based HIV-1 vaccine (MVA-B) in HIV-1-infected patients alone or in combination with a drug to reactivate latent HIV-1. J Antimicrob Chemother. 2015:70:1833-42

42. Cummins NW, Rizza S, Litzow MR, Hua S, Lee GQ, Einkauf K, et al. Extensive virologic and immunologic characterization in an HIV-infected individual following allogeneic stem cell transplant and analytic cessation of antiretroviral therapy: a case study. PLoS Med. 2017;14:e1002461.

43. ISALA. Analytical treatment interruption in HIV positive patients (ISALA). https://clinicaltrials.gov. NCT02590354.

44. Chun T-W, Murray D, Justement JS, Blazkova J, Hallahan CW, Fankuchen O, et al. Broadly neutralizing antibodies suppress HIV in the persistent viral reservoir. Proc Natl Acad Sci USA. 2014;111:13151-6.

45. Vibholm L, Schleimann MH, Højen JF, Benfield T, Offersen R, Rasmussen K, et al. Short-course toll-like receptor 9 agonist treatment impacts innate immunity and plasma viremia in individuals with human immunodeficiency virus infection. Clin Infect Dis. 2017:64:1686-95.

46. Rasmussen TA, Tolstrup M, Brinkmann CR, Olesen R, Erikstrup C, Solomon $A$, et al. Panobinostat, a histone deacetylase inhibitor, for latent-virus reactivation in HIV-infected patients on suppressive antiretroviral therapy: a phase 1/2, single group, clinical trial. Lancet HIV. 2014;1:e13-21.

47. Yucha RW, Hobbs KS, Hanhauser E, Hogan LE, Nieves W, Ozen MO, et al. High-throughput characterization of HIV-1 reservoir reactivation using a single-cell-in-droplet PCR assay. EBioMedicine. 2017:20:217-29.

48. Margolis DM, Archin NM. Proviral latency, persistent human immunodeficiency virus infection, and the development of latency reversing agents. J Infect Dis. 2017;215(suppl3):S111-8.

49. Søgaard OS, Graversen ME, Leth S, Olesen R, Brinkmann CR, Nissen SK, et al. The depsipeptide romidepsin reverses HIV-1 latency in vivo. PLoS Pathog. 2015;11:e1005142.

50. Paredes R, Vandekerkchove L, Clotet B, Moutchen M, De Wit S, Podzamczer D, et al. ABX464 decreases total HIV DNA in PBMC's when administered during 28 days to HIV-infected patients who are virologically suppressed. In: 9th IAS conference HIV Sci IAS 2017, Paris, France.

51. Bialek JK, Dunay GA, Voges M, Schäfer C, Spohn M, Stucka R, et al. Targeted HIV-1 latency reversal using CRISPR/Cas9-derived transcriptional activator systems. PLoS ONE. 2016;11:e0158294.

52. Tebas P, Stein D, Tang WW, Frank I, Wang SQ, Lee G, et al. Gene editing of CCR5 in autologous CD4 T cells of persons infected with HIV. N Engl J Med. 2014;370:901-10

53. Ho Y-C, Shan L, Hosmane NN, Wang J, Laskey SB, Rosenbloom DIS, et al. Replication-competent non-induced proviruses in the latent reservoir increase barrier to HIV-1 cure. Cell. 2013;155:540-51.

54. Anderson E, Hill S, Bell J, Simonetti FR, Rehm C, Jones S, et al. Accumulation and persistence of deleted HIV proviruses following prolonged ART. In: 9th IAS Conference HIV Sci IAS 2017, MOAA0102 Paris, France.

55. Maldarelli F, Wu X, Su L, Simonetti FR, Shao W, Hill S, et al. Specific HIV integration sites are linked to clonal expansion and persistence of infected cells. Science. 2014;345:179-83.

56. Regan JF, Kamitaki N, Legler T, Cooper S, Klitgord N, Karlin-Neumann G, et al. A rapid molecular approach for chromosomal phasing. PLOS ONE. 2015:10:e0118270. 